\title{
Hippocampal Sclerosis: Causes and Prevention
}

\author{
Matthew Charles Walker, FRCP, PhD ${ }^{1}$ \\ ${ }^{1}$ Department of Clinical and Experimental Epilepsy, UCL Institute of \\ Neurology, University College London, London, United Kingdom \\ Semin Neurol 2015;35:193-200.
}

\begin{abstract}
Address for correspondence Matthew Charles Walker, FRCP, PhD, Department of Clinical and Experimental Epilepsy, UCL Institute of Neurology, University College London, Queen Square, London WC1N 3BG, United Kingdom (e-mail: m.walker@ucl.ac.uk).
\end{abstract}

\begin{abstract}
Keywords

- hippocampal sclerosis

- status epileptics

- epilepsy

- neuroprotection

Hippocampal sclerosis is the commonest cause of drug-resistant epilepsy in adults, and is associated with alterations to structures and networks beyond the hippocampus. In addition to being a cause of epilepsy, the hippocampus is vulnerable to damage from seizure activity. In particular, prolonged seizures (status epilepticus) can result in hippocampal sclerosis. The hippocampus is also vulnerable to other insults including traumatic brain injury, and inflammation. Hippocampal sclerosis can occur in association with other brain lesions; the prevailing view is that it is probably a secondary consequence. In such instances, successful surgical treatment usually involves the resection of both the lesion and the involved hippocampus.

Experimental data have pointed to numerous neuroprotective strategies to prevent hippocampal sclerosis. Initial neuroprotective strategies aimed at glutamate receptors may be effective, but later, metabolic pathways, apoptosis, reactive oxygen species, and inflammation are involved, perhaps necessitating the use of interventions aimed at multiple targets.

Some of the therapies that we use to treat status epilepticus may neuroprotect. However, prevention of neuronal death does not necessarily prevent the later development of epilepsy or cognitive deficits. Perhaps, the most important intervention is the early, aggressive treatment of seizure activity, and the prevention of prolonged seizures.
\end{abstract}

The importance of the hippocampus as a cause of epilepsy was first recognized in 1825, when Bouchet and Cazauvielh described the pathology of 18 autopsied patients in a thesis that attempted to establish the relationship between epilepsy, "l'épilepsie," and insanity, "l'aliénation mentale."1 Later, Sommer (1880) described in detail the neuropathological finding of hippocampal sclerosis in the brains of patients with chronic epilepsy. ${ }^{2}$ He noted gliosis and pyramidal cell loss in predominantly the CA1 region of the hippocampus; he proposed that these lesions were the cause of the epilepsy.

Hippocampal sclerosis is now recognized as one of the main causes of focal epilepsy and is present in approximately $10 \%$ of adults with new-onset focal epilepsy. ${ }^{3}$ Moreover, hippocampal sclerosis often causes refractory epilepsy and is the sole pathology in about a third of all surgical resections for epilepsy and is an associated pathology (so-called dual pathology) in approximately $5 \%$.

Issue Theme Etiology of Epilepsy; Guest Editors: Philip Smith, MD, FRCP,

FAcadMEd, and Rhys Thomas, BSc, MRCP, MSc, PhD

However, the hippocampus has a twofold interest in epilepsy, as it also is an area of the brain that is particularly susceptible to damage by seizures (and other brain insults). This dichotomous role of hippocampal damage as the cause and result of seizures stems possibly from its physiological role in memory formation and neuronal plasticity. ${ }^{5}$

\section{Hippocampal Sclerosis Is More than One Condition}

Hippocampal sclerosis can have more than one cause, and often the cause is a complex interplay between genetic background and environmental insults (see below). However, hippocampal sclerosis is not even one neuropathological entity. ${ }^{6}$ Indeed, older systems of grading the severity of cell loss in hippocampal sclerosis ${ }^{7}$ have been superseded by a system that recognizes that it is not just the severity of cell

Copyright (C) 2015 by Thieme Medical Publishers, Inc., 333 Seventh Avenue, New York, NY 10001, USA. Tel: +1(212) 584-4662.
DOI http://dx.doi.org/ 10.1055/s-0035-1552618. ISSN 0271-8235. 
Table 1 International League Against Epilepsy classification of hippocampal sclerosis

\begin{tabular}{|c|c|}
\hline Type 1 & $\begin{array}{l}\text { CA1: }>80 \% \text { cell loss } \\
\text { CA2: } 30-50 \% \text { cell loss } \\
\text { CA3, } 30-90 \% \text { cell loss } \\
\text { CA4 } 40-90 \% \text { cell loss } \\
\text { Dentate gyrus } 50-60 \% \text { granule cell loss }\end{array}$ \\
\hline Type 2 & $\begin{array}{l}\text { Predominant neuronal loss in CA1, affecting almost } \\
80 \% \text { of pyramidal cells. All other sectors show mild cell } \\
\text { loss barely visible by qualitative microscopic inspection. }\end{array}$ \\
\hline Type 3 & $\begin{array}{l}\text { Predominant cell loss in CA } 4(\sim 50 \% \text { cell loss) and the dentate gyrus } \\
\text { (35\% cell loss), whereas CA3 }(<30 \%), \text { CA2 }(<25 \%) \text {, and CA1 } \\
(<20 \%) \text { are only moderately affected }\end{array}$ \\
\hline Type 4 & No hippocampal sclerosis and gliosis \\
\hline
\end{tabular}

Source: After Blümcke I, Thom M, Aronica E, et al. International consensus classification of hippocampal sclerosis in temporal lobe epilepsy: a Task Force report from the ILAE Commission on diagnostic methods. Epilepsia 2013;54(7):1315-1329.

loss that is important, but also the pattern of that cell loss. ${ }^{6}$ The new International League Against Epilepsy (ILAE) classification ( $\mathbf{- T a b l e ~ 1 , ~ - ~ F i g . ~ 1 ) ~ i n c o r p o r a t e s ~ s u c h ~ c o n c e p t s ~ a n d ~}$ grades hippocampal sclerosis as type 1, previously termed classical hippocampal sclerosis, occurring in 60 to $80 \%$ of resections; type 2, CA1 sclerosis, occurring in 5 to $10 \%$; type 3 , also termed end-folium sclerosis (mainly involving CA4 and dentate gyrus), occurring in 4 to $7 \%$ and gliosis without hippocampal sclerosis, which may be seen in up to $20 \%$ of temporal lobe resections. ${ }^{6}$

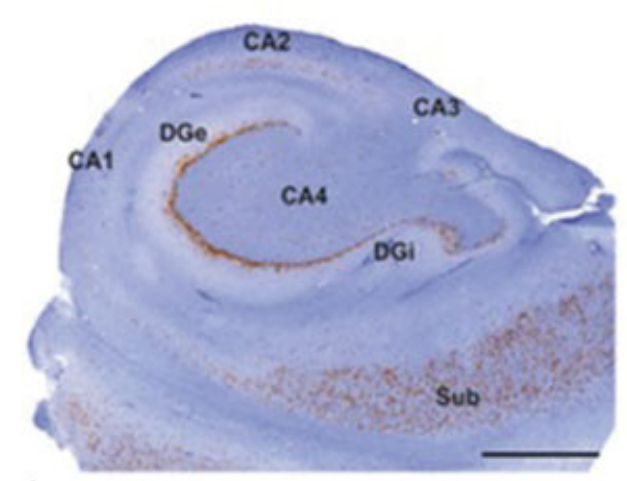

A
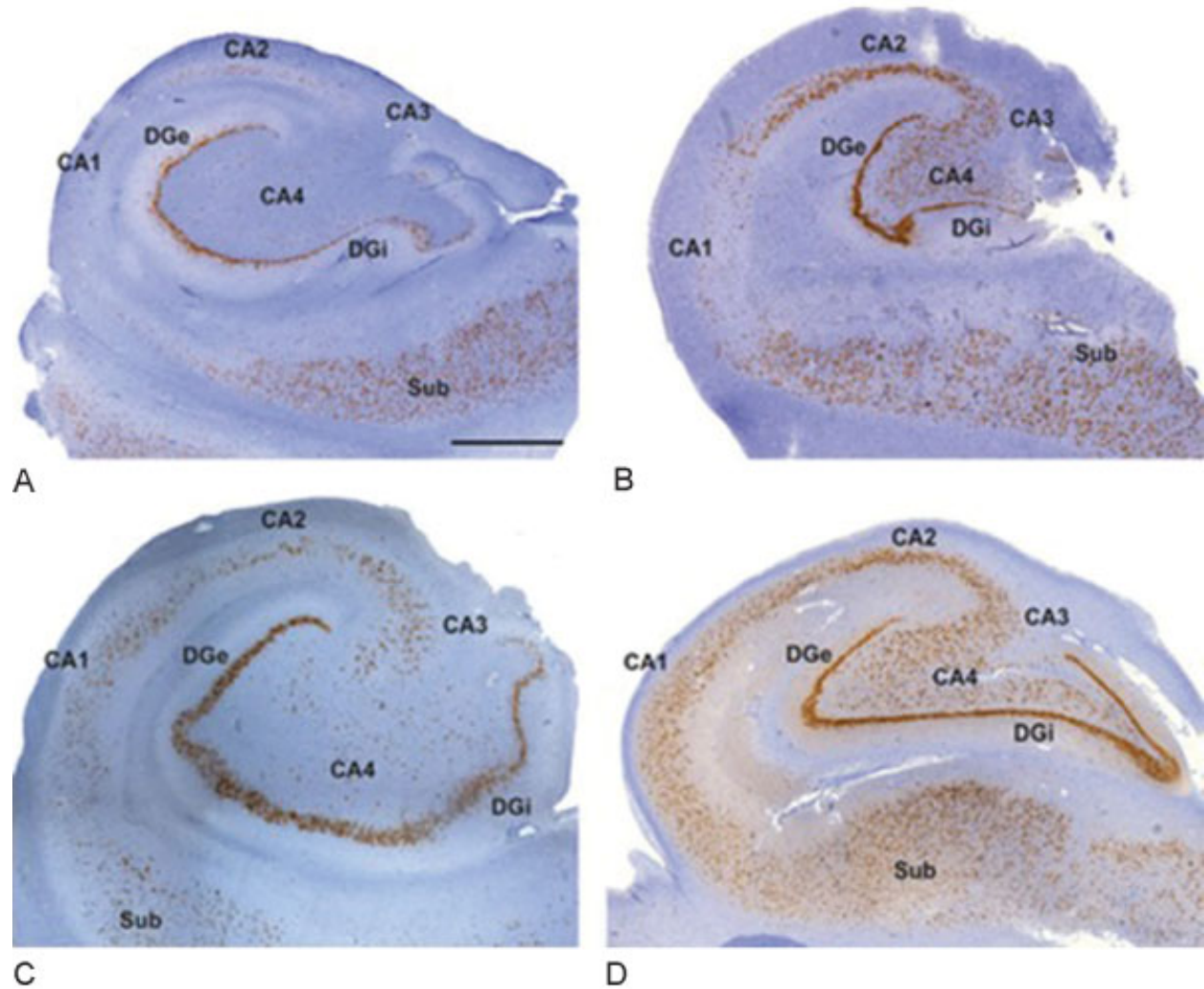

B

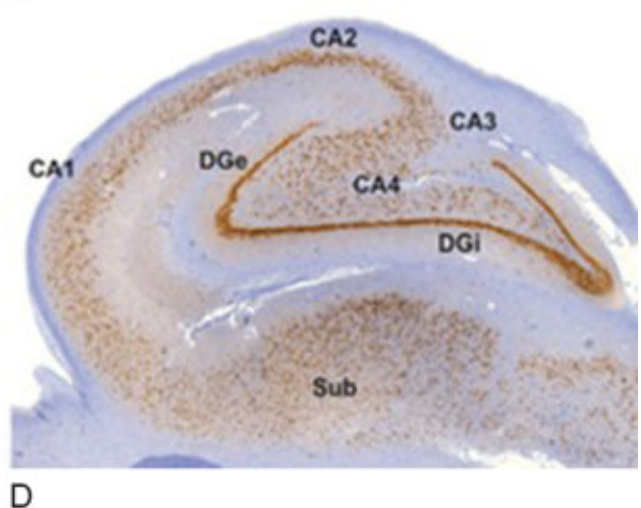

Fig. 1 Histopathologic subtypes of hippocampal sclerosis. (A) International League Against Epilepsy (ILAE) hippocampal sclerosis type 1 shows pronounced preferential pyramidal cell loss in both CA4 and CA1 sectors. Damage to sectors CA3 and CA2 is more variable but frequently visible. (B) ILAE hippocampal sclerosis type 2 (CA1 predominant neuronal cell loss and gliosis): This is a rarer and atypical hippocampal sclerosis pattern characterized by neuronal loss primarily involving CA1 compared with other subfields where damage is often not detectable by visual inspection (C) ILAE hippocampal sclerosis type 3 (CA4 predominant neuronal cell loss and gliosis): This is characterized by restricted cell loss mostly in CA4. (D) No hippocampal sclerosis, gliosis only. All stainings represent NeuN immunohistochemistry with hematoxylin counterstaining using 4- $\mu m$-thin paraffin embedded sections. DGe/DGI, external/internal limbs of dentate gyrus; Sub, subiculum. Scale bar in A = 1,000 $\mu \mathrm{m}$ (applies also to B-D). (Reprinted with permission from Blümcke I, Thom M, Aronica E, et al. International consensus classification of hippocampal sclerosis in temporal lobe epilepsy: a task force report from the ILAE Commission on diagnostic methods. Epilepsia 2013;54(7):1315-1329.) 
The classification is important because it may relate to surgical outcome-with the no hippocampal sclerosis but gliosis and the type 2 hippocampal sclerosis having the poorest outcomes ( $\sim 40 \%$ completely seizure free with 2 year follow-up) compared with approximately $70 \%$ seizure free with type 1 hippocampal sclerosis. ${ }^{8}$

The other important question is whether the pattern of damage relates to the nature of the precipitating event, age at the time of the precipitating event, and duration of epilepsy and seizure frequency. Interestingly, seizure frequency and duration of epilepsy had minimal impact on the type of hippocampal sclerosis. However, events before the age of 3 years tended to be associated with type 1 . Type 3 hippocampal sclerosis and no hippocampal sclerosis were less strongly associated with the occurrence of identifiable preceding events, which tended to happen later, during adolescence. $^{6}$

From a clinical perspective, it would be ideal to identify the pattern of cell loss before resection. Although magnetic resonance imaging (MRI) studies can reliably determine the severity of hippocampal sclerosis (confirmed by histopathology), ${ }^{9}$ automated programs with conventional clinical MRI (1.5 $\mathrm{T}$ or $3 \mathrm{~T}$ ) cannot yet reliably differentiate changes in specific hippocampal subfields. ${ }^{10}$ The severity of hippocampal sclerosis does not, however, directly translate to surgical success, but may impact the clinical pattern of the seizures, with more severe hippocampal sclerosis being associated with symptoms and signs that are usually ascribed to extratemporal lobe epilepsies. ${ }^{11}$ The challenge of identifying specific patterns of cell loss may be surmounted by increasingly sophisticated acquisition protocols at higher field strengths.

Neuronal loss and gliosis may extend beyond the hippocampus and affect the amygdala, parahippocampal gyrus, and entorhinal cortex. ${ }^{12,13}$ Entorhinal cortex neuronal loss has also been described in the absence of hippocampal sclerosis. ${ }^{14}$ This, and the observation that the entorhinal cortex can alone maintain seizure-like activity, ${ }^{15}$ suggests that there may an important role for this region in the generation of mesial temporal seizures.

Hippocampal sclerosis is also associated with brain abnormalities further afield, with neuronal loss reported in the thalamus. ${ }^{16}$ Indeed, thalamic atrophy seems a common finding, ${ }^{17}$ indicating that there are more widespread structural changes associated with hippocampal sclerosis, supporting the concept of medial temporal lobe epilepsy as a network phenomenon involving disparate brain areas. ${ }^{18}$ It is unclear whether the more widespread structural and functional abnormalities associated with hippocampal sclerosis are part of the syndrome or the result of secondary involvement of these regions due to repeated seizures generated from medial temporal structures. However, more widespread structural abnormalities detected by MRI do seem to predict poorer surgical outcomes. ${ }^{19}$

\section{Causes of Hippocampal Sclerosis}

In the same year that Sommer was proposing hippocampal sclerosis to be the cause of epilepsy, Pfleger published evi- dence that the hippocampus is particularly vulnerable to damage by seizures. ${ }^{20}$ Pfleger described hemorrhagic lesions in the mesial temporal lobe of a patient dying in status epilepticus, and concluded that neuronal necrosis was the result of impaired blood flow or metabolic disturbances that occurred during the seizures. More recent postmortem studies have also shown significant acute neuronal loss in the hippocampus of patients dying in convulsive status epilepticus. $^{21,22}$ DeGiorgio et al (1992) compared the hippocampi from five patients dying in status epilepticus, five patients with epilepsy who had a similar degree of physiological compromise (e.g., hypoglycemia, hypotension and hypoxia), and five controls. The neuronal densities were least in those dying with status epilepticus. ${ }^{21}$ Interestingly, a later unselected postmortem series identified that there are patients who have had a long history of seizures and even episodes of status epilepticus with no evidence of damage in the hippocampus, suggesting that status epilepticus alone may not be sufficient to cause neuronal damage. ${ }^{23}$

From the other perspective, a significant cerebral insult (or initial precipitating injury) occurring early in life, such as a febrile or prolonged seizure, is often reported (between 30 $50 \%$ of cases, but up to $80 \%$ in one surgical series) in retrospective studies of patients with hippocampal sclerosis. ${ }^{24}$ The "injury" hypothesis implies that this insult irreversibly damages or alters the hippocampus resulting in a template for the progression to hippocampal sclerosis following a "latent" interval. There appears to be an age-specific sensitivity for this injury, with more severe neuronal loss found when the initial precipitating injury occurs before ages of 4 to 7 years. ${ }^{25}$ The most direct evidence of the association is the observation with serial neuroimaging that hippocampal sclerosis may follow prolonged febrile convulsions. ${ }^{26}$ Approximately $10 \%$ of children with febrile seizures lasting $>30$ minutes (febrile status epilepticus) have an associated high T2-weighted signal in the hippocampus with later evolution to hippocampal sclerosis in most. ${ }^{27}$ In the other $90 \%$, there was evidence of decreased hippocampal growth, suggesting subtle hippocampal injury. ${ }^{27}$ Whether there were subtle abnormalities of the hippocampus that may have predisposed to hippocampal sclerosis was unclear. Importantly, in children, the development of hippocampal damage does not seem to be restricted to those who have had febrile status epilepticus, but can occur following any cause of convulsive status epilepticus. ${ }^{28}$

Head injury can also result in hippocampal sclerosis. In rat models, fluid percussion injury to the dura results in interneuron loss in the hippocampus. ${ }^{29}$ The mechanism by which this occurs is unknown. The neuronal loss is accompanied by enhanced excitability of the hippocampus, and eventually spontaneous seizures. Notably, the interneuronal loss is progressive, occurring months after the insult. ${ }^{30}$ An interesting observation in humans is that traumatic brain injury may be associated with covert status epilepticus that then results in hippocampal injury (-Fig. 2). ${ }^{31}$ These experimental and human studies raise a fundamental question: Why is it that only a minority develops hippocampal sclerosis following identical brain insults? 


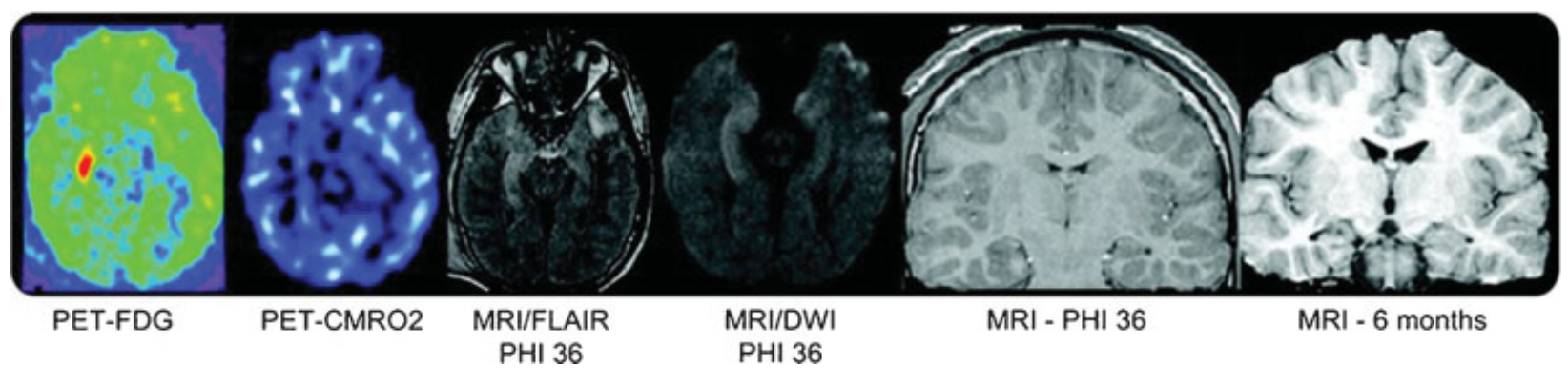

Fig. 2 Hippocampal atrophy ipsilateral to the seizure focus. The patient has increased glucose metabolism in the right hippocampus without a similar increase in CMRO2. The hyperintensity on the fluid-attenuated inversion recovery (FLAIR) sequence was due to acute seizure activity and not traumatic hemorrhage. Magnetic resonance imaging scan of brain at 6 months shows right hippocampal atrophy and also right temporal lobe atrophy. $\mathrm{CMRO2}=$ oxidative metabolism positron emission tomography (PET); FDG = fluorodeoxyglucose PET; PIH = postinjury hour. (Reprinted with permission from Vespa PM, McArthur DL, Xu Y, et al. Nonconvulsive seizures after traumatic brain injury are associated with hippocampal atrophy. Neurology 2010;75(9):792-798.)

Temporal lobe epilepsy is generally regarded as an acquired disorder with only a small genetic contribution. However, there may be common genetic variants that predispose to hippocampal sclerosis. Recently, such polymorphisms in a region of the genome encoding sodium channel subunits, in particular SCN1A, have been associated with the occurrence of febrile seizures and hippocampal sclerosis. ${ }^{32}$ This indicates that the risk of hippocampal sclerosis following a brain insult also depends upon the person's genetic background.

In addition, an underlying maldevelopment of the hippocampus could predispose to hippocampal sclerosis and also to febrile seizures ${ }^{33-35}$; this may partly explain why hippocampal sclerosis is often unilateral. In an MRI study of families with familial febrile convulsions, there were subtle pre-existing hippocampal abnormalities ${ }^{35}$ and hippocampal sclerosis has also been reported in patients in association with isolated malformations of the hippocampus. ${ }^{34}$ In addition, persistence of calretinin positive Cajal-Retzius cells may be found in the sclerosed hippocampus, particularly when associated with febrile seizures. ${ }^{33}$ These cells secrete reelin, which plays a critical role in neuronal organization in the developing brain; it is possible that their persistence is due to either a developmental abnormality or an "insult" that predated the febrile seizures. A further argument supporting a developmental basis for hippocampal sclerosis comes from the observation that hippocampal sclerosis is often observed in association with subtle cytoarchitectural malformations in the neocortex, such as microdysgenesis. ${ }^{36}$ There may, therefore, be a more widespread maldevelopmental process involving both mesial and lateral temporal lobe structures.

Hippocampal sclerosis is also well recognized to occur in association with more severe cortical malformations, vascular malformations, and low-grade glioneuronal tumors. ${ }^{37,38}$ Here, the hypothesis is that the extrahippocampal lesion generates seizures or subclinical seizure activity that results in neuronal loss in the hippocampus. In such patients (i.e., those with dual pathology), removing both the lesion and the abnormal hippocampus has the best outcome in terms of seizure control, emphasizing the role of the hippocampus in temporal lobe seizures even when there is a second pathology. ${ }^{38}$
Hippocampal sclerosis may be progressive in some patients, ${ }^{39}$ suggesting a paradigm in which an epileptogenic hippocampus generates seizures that then cause further damage to the hippocampus and more widespread structures, including the contralateral hippocampus. In support of this hypothesis, early surgical treatment (when the disease is more "confined") results in better outcomes than late surgical intervention. ${ }^{40}$

Lastly, infections can cause the hippocampal sclerosis. There is evidence that it can be associated with neurocysticercosis, although this is likely to be dual pathology rather than a direct impact on the hippocampus. ${ }^{41}$ Viral encephalitis often targets mesial temporal structures with the evolution to bilateral hippocampal sclerosis and profound memory difficulties emphasizing the importance of aggressive early treatment; hippocampal resection of those with an encephalitic etiology can still render people seizure free. ${ }^{42}$ Infection with herpes virus may also frequently underlie the occurrence of febrile seizures and later hippocampal sclerosis. ${ }^{43}$ More recently, autoimmune causes of hippocampal sclerosis have been identified, such as voltage-gated potassium channel antibodies. ${ }^{44}$ Usually, these autoantibodies result in an acute or subacute encephalitis with enlargement, increased T2weighted signal, and restricted diffusion of the mesial temporal lobe structures evident on MRI. Later, hippocampal sclerosis can occur, which may be unilateral or bilateral, again emphasizing the importance of aggressive early treatment. ${ }^{45}$ In some people with established hippocampal sclerosis, autoantibodies can be found, but it is unclear whether they are pathogenic or an epiphenomenon.

\section{Mechanisms of Neuronal Damage in Hippocampal Sclerosis and Pathways for Neuroprotection}

Insights into the mechanisms underlying hippocampal damage following prolonged seizures have largely been derived from animal models of status epilepticus. ${ }^{46,47}$ These have shown that although some neuronal damage is secondary to physiological compromise that occurs during status epilepticus, such as hypoxia, hypoglycemia, and hypotension, a large 
proportion of the damage is independent of these factors. This neuronal damage is due to excitotoxicity, in which the presence of epileptic activity mediates neuronal death through the activation of glutamate receptors. Excessive influx of calcium through primarily NMDA receptors, but also through specific AMPA receptor subtypes, and also activation of metabotropic glutamate receptors, results in a cascade of reactions leading to cell death. ${ }^{48-50}$ Undoubtedly, aggressive treatment of status epilepticus and limbic encephalitis is warranted. Moreover, prevention of physiological compromise during prolonged seizures through early transfer to intensive care unit is warranted. ${ }^{51}$ Beyond this, experimental studies have indicated that there may be other approaches to neuroprotection, although none have yet translated into human therapies.

\section{Prevention of Hippocampal Sclerosis}

\section{Endogenous Neuroprotection}

There are several endogenous neuroprotection pathways that could be targeted in neuroprotection. One important observation is that preconditioning (i.e., brief seizures protecting against longer seizures) seems to occur in epilepsy in a similar manner to that described in stroke. Such epileptic preconditioning alters gene expression in processes involved with calcium signaling, ion channels, and excitatory neurotransmitter receptors. ${ }^{52}$ These experimental observations suggest that the impact of status epilepticus may be less severe in people with pre-existing epilepsy.

What about specific pathways involved in neuroprotection? A variety of signaling pathways are involved in neuronal death and endogenous neuroprotection. Among these are the phosphoinositide 3-kinase (PI3-kinase)/Akt and the extracellular signal regulated kinase $1 / 2$ (ERK1/2) pathways that can be activated through several different routes including neurotrophins and calcium entry through NMDA receptors. The PI3 kinase/Akt pathway is intimately related to the mTOR pathway, inhibitors of which are being investigated for antiepileptogenic potential. $^{53}$ Phosphorylated (activated) Akt inactivates several proapoptotic proteins such as Bad, caspase-9, and transcription factors of the forkhead family. ${ }^{54-56}$ Thus, NMDA receptor activity can be neuroprotective. Indeed, NMDA receptor activation has a dichotomous role in neuronal survival/death; low level, chronic activation of synaptic NMDA receptors is neuroprotective, whereas sudden and excessive activation of extrasynaptic NMDA receptors is neurotoxic. $^{57}$

Reactive oxygen species can also play an important role in neuronal death. During seizure activity, these are also produced through the excessive activation of NMDA receptors and are mainly generated by cytosolic enzymes (such as NADPH oxidase). ${ }^{58}$ There are, however, endogenous mechanisms to protect against these: These endogenous mechanisms are boosted by the transcription factor, nuclear factor erythroid 2-related factor 2 (Nrf2). Nrf2 binds to the cisacting antioxidant response elements in the nucleus, a specific promoter sequence for genes encoding phase II and antioxidant cytoprotective proteins, including glutathione
S-transferase and NADPH:quinone oxidoreductase. ${ }^{59}$ There is evidence that the ketogenic diet upregulates $\mathrm{Nrf} 2$ and may mediate a neuroprotective effect through this mechanism. ${ }^{60}$ However, reactive oxygen species also show a dichotomous role. Peroxynitrite, which is a potent reactive oxygen species that can result in neuronal death, at very low concentrations activates the Akt pathway and thus may be neuroprotective. ${ }^{61}$ ERK1/2 can be activated by a variety of extracellular stimuli including neurotrophins. ${ }^{62}$ ERK1/2 activation may initially counter oxidative stress, but when cellular defenses are exhausted, it serves as a signal to trigger cell death. ${ }^{63}$

Together, many of these studies indicate that the binary view of many of these enzymes, receptors, and pathways as neurotoxic or neuroprotective is far too simplistic, and there is often a form of dualism with pathways having both neuroprotective and neurotoxic potential.

\section{Exogenous Neuroprotection}

Undoubtedly, the most effective way to prevent seizurerelated damage is to halt seizure activity. Indeed, the treatment of status epilepticus in the premonitory phases before status epilepticus has become established may prevent many of the pathological consequences. ${ }^{64}$ Therefore, early recognition and administration of effective treatment are paramount. If seizures continue, then the excitotoxic cascade is activated. The NMDA receptor and metabotropic glutamate group I receptor activation result in both calcium influx into the neuron and also release of calcium from internal stores. ${ }^{65}$ Other receptors and ion channels, such as voltage-gated calcium channels and calcium-permeable AMPA receptors, may also contribute to intracellular calcium accumulation. In addition, seizure-induced ion shifts may cause neuronal swelling and necrotic cell death. Inhibition of NMDA receptors before or soon after status epilepticus gives substantial and widespread neuroprotection, ${ }^{66}$ but it is likely that NMDA receptor antagonists will need to be given early to prevent calcium accumulation.

Calcium accumulation activates many distinct and interconnected downstream mechanisms, including the extrinsic caspase pathway through caspase 8 activation, the intrinsic caspase pathway activated by cytochrome c release from mitochondria, BCL-2 pathways, the formation of reactive oxygen species such as peroxynitrite, disruption of mitochondrial function through mitochondrial calcium accumulation, activation of calpain 1 , activation of poly(ADP-ribose) polymerase- 1 , and so forth. ${ }^{67-69}$ There is considerable controversy about the relative roles of these different pathways. This whole area is further confounded by the possibility that different pathways are activated in different seizure models at different times, and that the mechanism of neuronal death may be region/cell specific. ${ }^{70}$ There are, however, simple measures that could be used to neuroprotect, such as anaplerosis, the replenishment of Krebs' cycle substrates. ${ }^{71}$ Indeed, the ketogenic diet could contribute to neuroprotection through this mechanism.

Independent from neuronal calcium accumulation, inflammatory mechanisms have also been implicated in neuronal death and dysfunction during prolonged seizures, and 
interventions targeted at brain inflammation in experimental model have shown some success. ${ }^{72}$

Clinically, an important question is whether antiepileptic (antiseizure) drugs have any neuroprotective roles beyond their antiseizure effect. There is reasonable preclinical evidence that many of our present antiepileptic drugs have potential neuroprotective properties, but the mechanisms underlying this are not fully elucidated. ${ }^{73}$ Furthermore, many of the preclinical studies are confounded by an effect of drugs on seizure severity, making it difficult to dissociate the antiseizure from the neuroprotective effect.

\section{Neuroprotection, Epileptogenesis, and Cognitive Decline}

Does preventing neuronal death prevent other consequences from a brain insult? There is a clear distinction between preventing neuronal death and preventing the later development of epilepsy; indeed, some endogenous neuroprotective pathways could be proepileptogenic by encouraging axonal reorganization and potentiating synaptic transmission. Preventing calcium accumulation by inhibiting NMDA receptor should prevent the downstream consequences. Indeed, NMDA receptor antagonists seem to prevent not only neuronal death, but also subsequent cognitive effects and epileptogenesis. ${ }^{74,75}$ However, NMDA receptor antagonism may not always be sufficient to prevent the development of epilepsy, even when it has prevented the neuronal damage. $^{76}$

This disconnect between neuronal death and clinical consequences can be explained by recognizing that brain injury results in not only neuronal death alone, but also neurogenesis, selective death of specific neuronal populations, synaptic reorganization, and changes in neuronal behavior. ${ }^{5}$ Although neuronal death may be a driver for some of these consequences, it is not necessary and thus its prevention does not necessarily prevent the development of epilepsy or cognitive consequences.

\section{Conclusion}

Hippocampal sclerosis has been established as both the cause and the consequence of epilepsy, but it represents much more than neuronal death confined to the hippocampus. Hippocampal sclerosis is characterized by not only neuronal death but also alterations in neuronal connectivity and network behavior that underlie the development of chronic epilepsy and memory deficits. Moreover, it is the tip of the iceberg, as there is growing evidence of more distributed abnormalities that become more marked with time. Thus, prevention of neuronal death may not be sufficient to prevent these other processes.

Nevertheless, prompt and aggressive treatment of prolonged seizures could prevent hippocampal sclerosis and its consequences. If seizures continue, there is some evidence supporting neuroprotective effects of some of our present antiepileptic (antiseizure) drugs, and of interventions such as anti-inflammatory drugs and the ketogenic diet. Whether other interventions such as more aggressive immunomodulation, antiapoptotic agents and therapies aimed against reactive oxygen species have any clinical benefit remains unclear. The growing number of pathways and mechanisms involved in neuronal death, epileptogenesis, and cognitive decline following a neuronal insult indicate that it is unlikely that one target will be sufficient, and that there may need to be therapies aimed at multiple targets, and these targets may vary depending upon the nature of the insult and the genetic background of the individual.

\section{Acknowledgments}

I thank Epilepsy Research UK and FP7-HEALTH project 602102 (EPITARGET) for their support. This work was undertaken at University College London Hospitals/ University College London, which receives a proportion of funding from the Department of Health National Institute for Health Research Biomedical Research Centres' funding scheme.

\section{References}

1 Bouchet C, Cazavieilh J. De L'epilpsie consideree dans ses raports avec l'alienation mentale. Recherche sur la nature et le siege de ces deux maladies. Arch Gen Med. 1825;9:510-542

2 Sommer W. Erkrankung des ammonshornes als aetiologisches moment der epilepsie. Arch Psychiatr Nervenkr 1880;10:631-675

3 Van Paesschen W, Duncan JS, Stevens JM, Connelly A. Longitudinal quantitative hippocampal magnetic resonance imaging study of adults with newly diagnosed partial seizures: one-year follow-up results. Epilepsia 1998;39(6):633-639

4 Blümcke I, Spreafico R. Cause matters: a neuropathological challenge to human epilepsies. Brain Pathol 2012;22(3):347-349

5 Walker M, Chan D, Thom M. Hippocampus and human disease. In: Andersen P, Morris R, Amaral D, Bliss T, O'Keefe J, eds. The Hippocampus Book. Oxford: Oxford University Press; 2007: 769-812

6 Blümcke I, Thom M, Aronica E, et al. International consensus classification of hippocampal sclerosis in temporal lobe epilepsy: a Task Force report from the ILAE Commission on diagnostic methods. Epilepsia 2013;54(7):1315-1329

7 Wyler AR, Curtis Dohan F, Schweitzer JB, Berry AD. A grading system for mesial temporal pathology (hippocampal sclerosis) from anterior temporal lobectomy. J Epilepsy 1992;5(4):220-225

8 Thom M, Liagkouras I, Elliot KJ, et al. Reliability of patterns of hippocampal sclerosis as predictors of postsurgical outcome. Epilepsia 2010;51(9):1801-1808

9 Watson C, Nielsen SL, Cobb C, Burgerman R, Williamson B. Pathological grading system for hippocampal sclerosis: correlation with magnetic resonance imaging-based volume measurements of the hippocampus. J Epilepsy 1996;9(1):56-64

10 Schoene-Bake J-C, Keller SS, Niehusmann P, et al. In vivo mapping of hippocampal subfields in mesial temporal lobe epilepsy: relation to histopathology. Hum Brain Mapp 2014; 35(9):4718-4728

11 Borelli P, Shorvon SD, Stevens JM, Smith SJ, Scott CA, Walker MC Extratemporal ictal clinical features in hippocampal sclerosis: their relationship to the degree of hippocampal volume loss and to the outcome of temporal lobectomy. Epilepsia 2008;49(8): 1333-1339

12 Bernasconi N, Bernasconi A, Caramanos Z, Antel SB, Andermann F, Arnold DL. Mesial temporal damage in temporal lobe epilepsy: a 
volumetric MRI study of the hippocampus, amygdala and parahippocampal region. Brain 2003;126(Pt 2):462-469

13 Yilmazer-Hanke DM, Wolf HK, Schramm J, Elger CE, Wiestler OD, Blümcke I. Subregional pathology of the amygdala complex and entorhinal region in surgical specimens from patients with pharmacoresistant temporal lobe epilepsy. J Neuropathol Exp Neurol 2000;59(10):907-920

14 Bernasconi N, Bernasconi A, Caramanos Z, et al. Entorhinal cortex atrophy in epilepsy patients exhibiting normal hippocampal volumes. Neurology 2001;56(10):1335-1339

15 Jones RS. Ictal epileptiform events induced by removal of extracellular magnesium in slices of entorhinal cortex are blocked by baclofen. Exp Neurol 1989;104(2):155-161

16 Sinjab B, Martinian L, Sisodiya SM, Thom M. Regional thalamic neuropathology in patients with hippocampal sclerosis and epilepsy: a postmortem study. Epilepsia 2013;54(12):2125-2133

17 Barron DS, Fox PM, Laird AR, Robinson JL, Fox PT. Thalamic medial dorsal nucleus atrophy in medial temporal lobe epilepsy: a VBM meta-analysis. Neuroimage Clin 2012;2:25-32

18 Coan AC, Campos BM, Yasuda CL, et al. Frequent seizures are associated with a network of gray matter atrophy in temporal lobe epilepsy with or without hippocampal sclerosis. PLoS ONE 2014; 9(1):e85843

19 Keller SS, Richardson MP, Schoene-Bake J-C, et al. Thalamotemporal alteration and postoperative seizures in temporal lobe epilepsy. Ann Neurol 2015; Epub ahead of print

20 Pfleger L. Beobachtungen uber schrumpfung und sclerose des ammonshornes bei epilepsie. Allg Zeitschrift für Psychiatr 1880; 36:359-365

21 DeGiorgio CM, Tomiyasu U, Gott PS, Treiman DM. Hippocampal pyramidal cell loss in human status epilepticus. Epilepsia 1992; 33(1):23-27

22 Corsellis JA, Bruton CJ. Neuropathology of status epilepticus in humans. Adv Neurol 1983;34:129-139

23 Thom M, Zhou J, Martinian L, Sisodiya S. Quantitative post-mortem study of the hippocampus in chronic epilepsy: seizures do not inevitably cause neuronal loss. Brain 2005;128(Pt 6):1344-1357

24 French JA, Williamson PD, Thadani VM, et al. Characteristics of medial temporal lobe epilepsy: I. Results of history and physical examination. Ann Neurol 1993;34(6):774-780

25 Davies KG, Hermann BP, Dohan FC Jr, Foley KT, Bush AJ, Wyler AR. Relationship of hippocampal sclerosis to duration and age of onset of epilepsy, and childhood febrile seizures in temporal lobectomy patients. Epilepsy Res 1996;24(2):119-126

26 Lewis DV, Barboriak DP, MacFall JR, Provenzale JM, Mitchell TV, VanLandingham KE. Do prolonged febrile seizures produce medial temporal sclerosis? Hypotheses, MRI evidence and unanswered questions. Prog Brain Res 2002;135:263-278

27 Lewis DV, Shinnar S, Hesdorffer DC, et al; FEBSTAT Study Team. Hippocampal sclerosis after febrile status epilepticus: the FEBSTAT study. Ann Neurol 2014;75(2):178-185

28 Yoong M, Martinos MM, Chin RF, Clark CA, Scott RC. Hippocampal volume loss following childhood convulsive status epilepticus is not limited to prolonged febrile seizures. Epilepsia 2013;54(12): 2108-2115

29 Lowenstein DH, Thomas MJ, Smith DH, McIntosh TK. Selective vulnerability of dentate hilar neurons following traumatic brain injury: a potential mechanistic link between head trauma and disorders of the hippocampus. J Neurosci 1992;12(12):4846-4853

30 Pavlov I, Huusko N, Drexel M, et al. Progressive loss of phasic, but not tonic, GABAA receptor-mediated inhibition in dentate granule cells in a model of post-traumatic epilepsy in rats. Neuroscience 2011;194:208-219

31 Vespa PM, McArthur DL, Xu Y, et al. Nonconvulsive seizures after traumatic brain injury are associated with hippocampal atrophy. Neurology 2010;75(9):792-798

32 Kasperaviciute D, Catarino CB, Matarin M, et al; UK Brain Expression Consortium. Epilepsy, hippocampal sclerosis and febrile seizures linked by common genetic variation around SCN1A. Brain 2013;136(Pt 10):3140-3150

33 Blümcke I, Thom M, Wiestler OD. Ammon's horn sclerosis: a maldevelopmental disorder associated with temporal lobe epilepsy. Brain Pathol 2002;12(2):199-211

34 Baulac M, De Grissac N, Hasboun D, et al. Hippocampal developmental changes in patients with partial epilepsy: magnetic resonance imaging and clinical aspects. Ann Neurol 1998;44(2): 223-233

35 Fernández G, Effenberger O, Vinz B, et al. Hippocampal malformation as a cause of familial febrile convulsions and subsequent hippocampal sclerosis. Neurology 1998;50(4):909-917

36 Hardiman O, Burke T, Phillips J, et al. Microdysgenesis in resected temporal neocortex: incidence and clinical significance in focal epilepsy. Neurology 1988;38(7):1041-1047

37 Cendes F, Cook MJ, Watson C, et al. Frequency and characteristics of dual pathology in patients with lesional epilepsy. Neurology 1995; 45(11):2058-2064

38 Li LM, Cendes F, Andermann F, et al. Surgical outcome in patients with epilepsy and dual pathology. Brain 1999;122(Pt 5):799-805

39 Briellmann RS, Berkovic SF, Syngeniotis A, King MA, Jackson GD. Seizure-associated hippocampal volume loss: a longitudinal magnetic resonance study of temporal lobe epilepsy. Ann Neurol 2002; 51(5):641-644

40 Janszky J, Janszky I, Schulz R, et al. Temporal lobe epilepsy with hippocampal sclerosis: predictors for long-term surgical outcome. Brain 2005;128(Pt 2):395-404

41 Bianchin MM, Velasco TR, Santos AC, Sakamoto AC. On the relationship between neurocysticercosis and mesial temporal lobe epilepsy associated with hippocampal sclerosis: coincidence or a pathogenic relationship? Pathog Glob Health 2012;106(5): 280-285

42 Davies KG, Hermann BP, Wyler AR. Surgery for intractable epilepsy secondary to viral encephalitis. Br J Neurosurg 1995;9(6):759-762

43 Epstein LG, Shinnar S, Hesdorffer DC, et al; FEBSTAT study team. Human herpesvirus 6 and 7 in febrile status epilepticus: the FEBSTAT study. Epilepsia 2012;53(9):1481-1488

44 Vincent A, Buckley C, Schott JM, et al. Potassium channel antibodyassociated encephalopathy: a potentially immunotherapy-responsive form of limbic encephalitis. Brain 2004;127(Pt 3): 701-712

45 Wagner J, Witt J-A, Helmstaedter C, Malter MP, Weber B, Elger CE. Automated volumetry of the mesiotemporal structures in antibody-associated limbic encephalitis. J Neurol Neurosurg Psychiatry 2014; (e-pub ahead of print)

46 Meldrum B. Excitotoxicity and epileptic brain damage. Epilepsy Res 1991;10(1):55-61

47 Collins RC, Lothman EW, Olney JW. Status epilepticus in the limbic system: biochemical and pathological changes. Adv Neurol 1983; 34:277-288

48 Tanaka H, Grooms SY, Bennett MV, Zukin RS. The AMPAR subunit GluR2: still front and center-stage. Brain Res 2000;886(1-2): 190-207

49 Weiss JH, Sensi SL. Ca2+-Zn2+ permeable AMPA or kainate receptors: possible key factors in selective neurodegeneration. Trends Neurosci 2000;23(8):365-371

50 Lipton SA, Rosenberg PA. Excitatory amino acids as a final common pathway for neurologic disorders. N Engl J Med 1994;330(9): 613-622

51 Walker M. Status epilepticus: an evidence based guide. BMJ 2005; 331(7518):673-677

52 Jimenez-Mateos EM, Hatazaki S, Johnson MB, et al. Hippocampal transcriptome after status epilepticus in mice rendered seizure damage-tolerant by epileptic preconditioning features suppressed calcium and neuronal excitability pathways. Neurobiol Dis 2008; 32(3):442-453

53 Ostendorf AP, Wong M. mTOR Inhibition in Epilepsy: Rationale and Clinical Perspectives. CNS Drugs 2015;29(2):91-99 
54 Cardone MH, Roy N, Stennicke HR, et al. Regulation of cell death protease caspase- 9 by phosphorylation. Science 1998;282(5392): 1318-1321

55 Datta SR, Dudek H, Tao X, et al. Akt phosphorylation of BAD couples survival signals to the cell-intrinsic death machinery. Cell 1997;91(2):231-241

56 Brunet A, Bonni A, Zigmond MJ, et al. Akt promotes cell survival by phosphorylating and inhibiting a Forkhead transcription factor. Cell 1999;96(6):857-868

57 Hardingham GE, Bading H. Synaptic versus extrasynaptic NMDA receptor signalling: implications for neurodegenerative disorders. Nat Rev Neurosci 2010;11(10):682-696

58 Kovac S, Domijan A-M, Walker MC, Abramov AY. Seizure activity results in calcium- and mitochondria-independent ROS production via NADPH and xanthine oxidase activation. Cell Death Dis 2014;5:e1442

59 Baird L, Dinkova-Kostova AT. The cytoprotective role of the Keap1Nrf2 pathway. Arch Toxicol 2011;85(4):241-272

60 Milder JB, Liang L-P, Patel M. Acute oxidative stress and systemic Nrf2 activation by the ketogenic diet. Neurobiol Dis 2010;40(1):238-244

61 Delgado-Esteban M, Martin-Zanca D, Andres-Martin L, Almeida A, Bolaños JP. Inhibition of PTEN by peroxynitrite activates the phosphoinositide-3-kinase/Akt neuroprotective signaling pathway. J Neurochem 2007;102(1):194-205

62 Hetman M, Gozdz A. Role of extracellular signal regulated kinases 1 and 2 in neuronal survival. Eur J Biochem 2004;271(11):2050-2055

63 Luo Y, DeFranco DB. Opposing roles for ERK1/2 in neuronal oxidative toxicity: distinct mechanisms of ERK1/2 action at early versus late phases of oxidative stress. J Biol Chem 2006;281(24): 16436-16442

64 Treiman DM, Walker MC. Treatment of seizure emergencies: convulsive and non-convulsive status epilepticus. Epilepsy Res 2006;68(Suppl 1):S77-S82
65 Meldrum BS. Implications for neuroprotective treatments. Prog Brain Res 2002;135:487-495

66 Fujikawa DG, Daniels AH, Kim JS. The competitive NMDA receptor antagonist CGP 40116 protects against status epilepticus-induced neuronal damage. Epilepsy Res 1994;17(3):207-219

67 Rowley S, Patel M. Mitochondrial involvement and oxidative stress in temporal lobe epilepsy. Free Radic Biol Med 2013; 62:121-131

68 Henshall DC, Simon RP. Epilepsy and apoptosis pathways. J Cereb Blood Flow Metab 2005;25(12):1557-1572

69 Fujikawa DG. Prolonged seizures and cellular injury: understanding the connection. Epilepsy Behav 2005;7(Suppl 3):S3-S11

70 Narkilahti S, Pirttilä TJ, Lukasiuk K, Tuunanen J, Pitkänen A. Expression and activation of caspase 3 following status epilepticus in the rat. Eur J Neurosci 2003;18(6):1486-1496

71 Kovac S, Abramov AY, Walker MC. Energy depletion in seizures: anaplerosis as a strategy for future therapies. Neuropharmacology 2013;69:96-104

72 Vezzani A, Aronica E, Mazarati A, Pittman QJ. Epilepsy and brain inflammation. Exp Neurol 2013;244:11-21

73 Pitkänen A, Kubova H. Antiepileptic drugs in neuroprotection. Expert Opin Pharmacother 2004;5(4):777-798

74 Rice AC, Floyd CL, Lyeth BG, Hamm RJ, DeLorenzo RJ. Status epilepticus causes long-term NMDA receptor-dependent behavioral changes and cognitive deficits. Epilepsia 1998;39(11): $1148-1157$

75 Prasad A, Williamson JM, Bertram EH. Phenobarbital and MK-801, but not phenytoin, improve the long-term outcome of status epilepticus. Ann Neurol 2002;51(2):175-181

76 Brandt C, Potschka H, Löscher W, Ebert U. N-methyl-D-aspartate receptor blockade after status epilepticus protects against limbic brain damage but not against epilepsy in the kainate model of temporal lobe epilepsy. Neuroscience 2003;118(3):727-740 